\title{
The Carolina Bridge—An Interim Fixed Prosthesis: A Case Report
}

\author{
Tushar $^{1}$, Aditya Chaudhary ${ }^{2}$, Srishti Garg ${ }^{3}$, Shubham Gupta ${ }^{4}$, Anuraj Vijayan ${ }^{5}$
}

\begin{abstract}
Various resin-bonded bridges are available and documented in the literature for many years as both temporary and permanent restorations for single missing anterior tooth and posterior tooth. All of the resin-bonded fixed partial prostheses require some amount of tooth preparation, and as we are practicing more conservative approaches toward restoring single missing teeth, a CAROLINA BRIDGE, which requires no significant tooth preparation making it an excellent choice as an interim fixed prosthesis. The success of this prosthesis completely depends upon the interproximal surface area.

Keywords: Carolina bridge, Conservative technique, Interim restoration, Resin-bonded fixed dental prosthesis.

Journal of Operative Dentistry and Endodontics (2020): 10.5005/jp-journals-10047-0100
\end{abstract}

\section{INTRODUCTION}

The purpose of this case report is to present a possible approach for the replacement of single missing incisors using a customfabricated resin bonded pontic, the Carolina bridge.

This name was coined by Drake Precision Dental Lab of Charlotte, North Carolina, USA, in the late 1990s. It was first used by Heymann in 1987, ${ }^{1}$ this simple design consists of a custommade all-porcelain pontic with an etched proximal surface that bonds to the adjacent abutment teeth using resin composite connectors. ${ }^{2}$

The primary qualities of this type of bonded bridge are ease of placement, esthetic vitality (no metal substructure), ease of connector repair, and a totally reversible nature. As with all bonded bridges, the primary keys to success include the availability of adequate surface area for bonding, commending occlusion, and periodontally sound and stable abutment teeth.,

\section{Case Description}

A 25-year-old female patient reported to the department with the chief complaint of irksome smile; on clinical examination, it was revealed that the patient has decayed 22 and peg lateral in 12 along with deep bite. The patient was suggested to go for extraction in 22 followed by an immediate implant placement in 22. As the implant has been placed in the region of 22, it was advisable to give interim prosthesis in 22 to prevent space closer by drifting of 21 and 23 , So Carolina bridge was planned in this case, which requires no significant tooth preparation (Fig. 1).

\section{Steps}

- PMMA acrylic teeth were selected according to the space available and mold was fabricated for that acrylic tooth. To this mold, the composite was packed layer by layer and cured to obtain the full composite teeth (Figs. 2 and 3).

- The teeth are then thoroughly rinsed, proximal surfaces of the tooth were slightly roughened using diamond burs, to increase the surface area.

- Etching the proximal surface of tooth and pontics fabricated for 15 seconds using 35\% phosphoric acid etching gel (Fig. 4).
${ }^{1}$ ITS Dental College Hospital and Research Centre, Greater Noida, Uttar Pradesh, India

${ }^{2-5}$ Department of Prosthodontics, Crown and Bridge, ITS Dental College Hospital and Research Centre, Greater Noida, Uttar Pradesh, India

Corresponding Author: Tushar, ITS Dental College Hospital and Research Centre, Greater Noida, Uttar Pradesh, India, Phone: +91 09990026806, e-mail: tushar1994rishu@gmail.com

How to cite this article:Tushar, Chaudhary A, Garg S, et al. The Carolina Bridge-An Interim Fixed Prosthesis: A Case Report. J Oper Dent Endod 2020;5(2):105-106.

Source of support: Nil

Conflict of interest: None

- Bonding agent is applied onto the tooth and cured for 20 seconds (Figs. 5 and 6).

- A small amount of resin composite was applied to the proximal surfaces of the pontic as well as teeth. Pontic was then placed between the teeth and cured (Fig. 7).

- The patient has been instructed for proper oral hygiene techniques, including the correct use of a floss threader to access the underside of the pontic. The patient is once again reminded to avoid biting hard foods or objects to prevent fracture of connector areas.

\section{Discussion}

Carolina bridges are best suited for young patients with missing anterior teeth; ideally, lateral incisors missing cases are best treated by this prosthesis. ${ }^{5}$ Carolina bridge requires no significant tooth preparation, which makes it entirely reversible. The abutment teeth can be returned to their original virgin condition simply by removing the bonded pontic and the resin composite connectors. Carolina bridges are not preferred for the replacement of posterior teeth or canines because of the degree of occlusal stress encountered in these areas. Minimum incisogingival height of $5 \mathrm{~mm}$ is needed along the proximal surface of teeth to guarantee adequate bonding. ${ }^{6}$ 


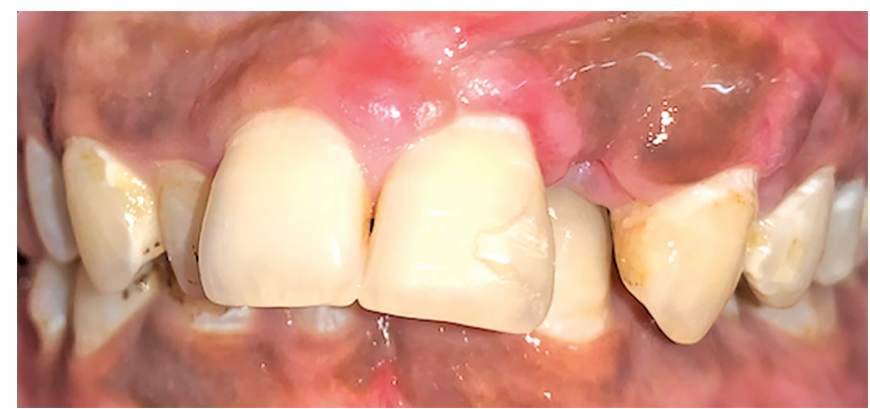

Fig. 1: Intraoral image representing missing lateral incisors

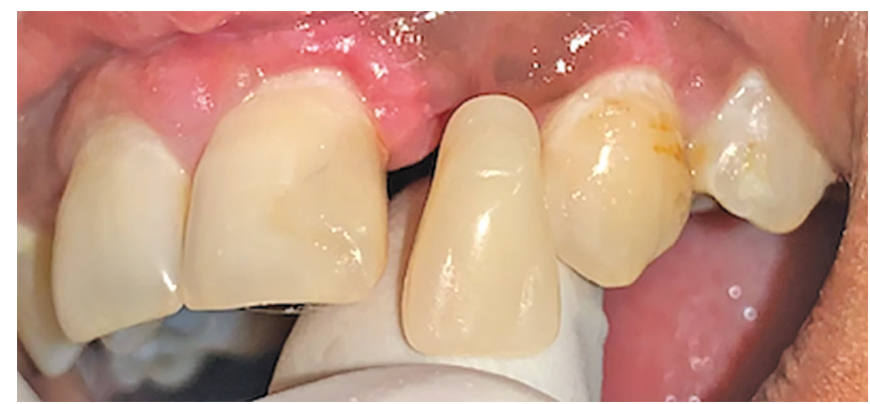

Fig. 2: PMMA acrylic tooth size was measured

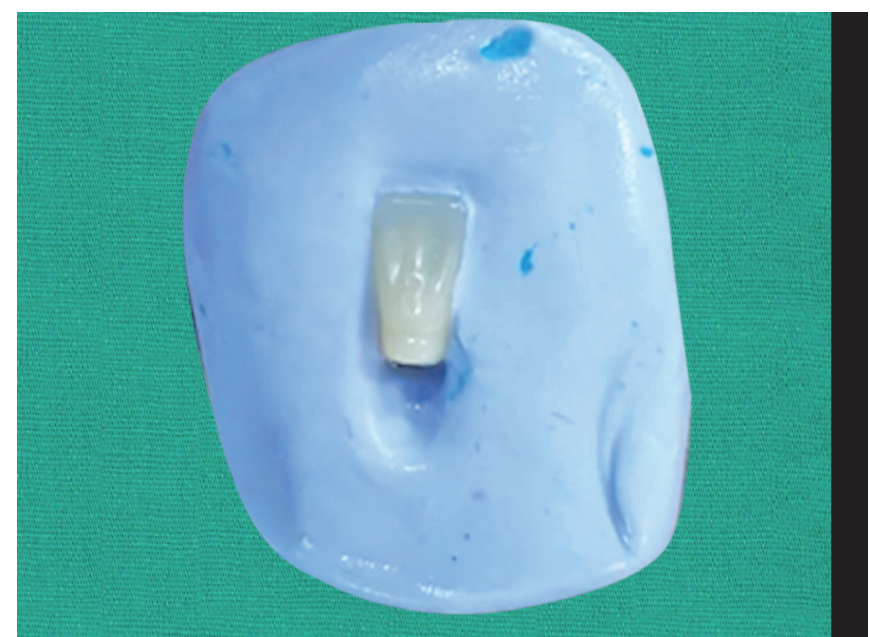

Fig. 3: Putty mold for lateral incisors was made

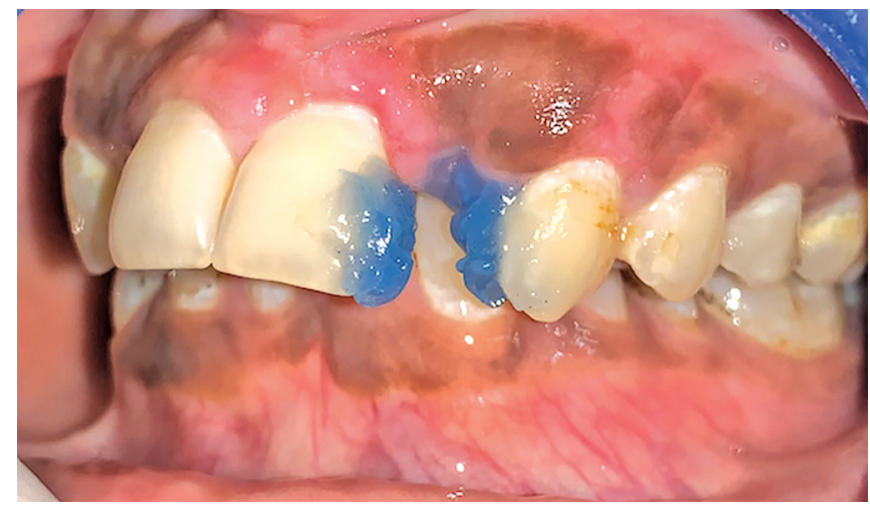

Fig. 4: Etching done with 35\% phosphoric acid for 15 seconds

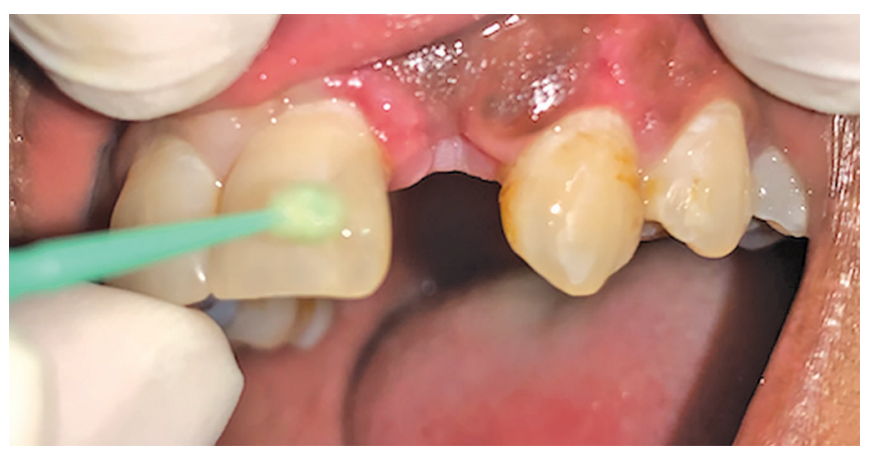

Fig. 5: Application of bonding agent

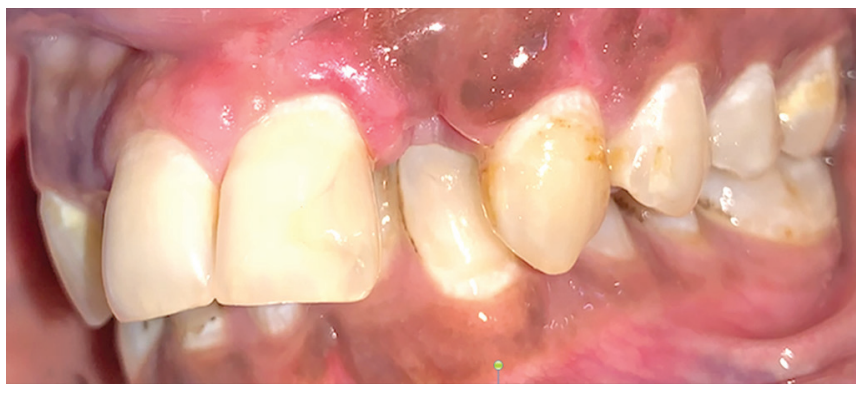

Fig. 6: Bonding agent cured for 20 seconds

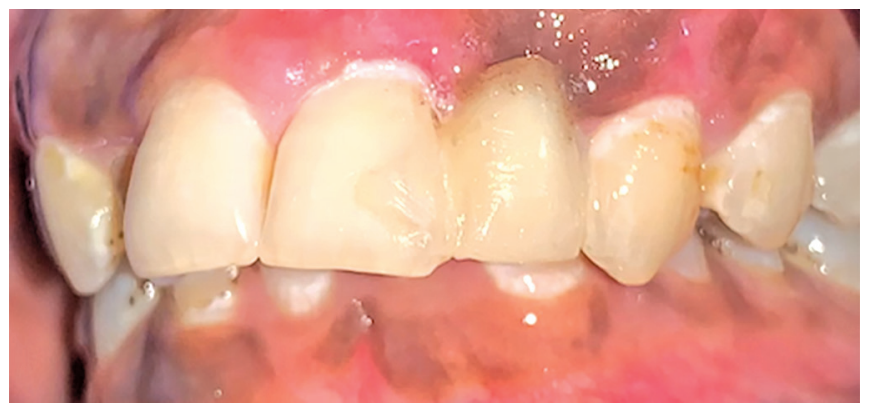

Fig. 7: Final outcome of prosthesis (Carolina bridge)

\section{SUMMARY}

The Carolina bridge is a novel resin-bonded prosthesis that can be set out as an exceptional interim prosthesis for the replacement of single anterior incisors.

\section{References}

1. Heymann HO. Additional conservative esthetic procedures. In: Roberson TM, editor. The art and science of operative dentistry. 4th ed. St. Louis: CV Mosby Co; 2001. p. 592-649.2.

2. Heymann HO. The Carolina bridge: a novel interim all-porcelain bonded prosthesis. J Esthet Restor Dent 2006;18(2):81-92. DOI: 10.2310/6130.2006.00014_1.x.

3. Livaditis G, Thompson VP. Etched castings: an improved retentive mechanism for resinbonded retainers. J Prosthet Dent 1982;47(1):52. DOI: 10.1016/0022-3913(82)90242-6.

4. Rochette AL. Attachment of a splint to enamel of lower anterior teeth. J Prosthet Dent 1973;30(4 Pt 1):418. DOI: 10.1016/0022-3913(73)90163-7.

5. Moore DL, Demke R, Eick JD, et al. Retentive strength of anterior etched porcelain bridges attached with resin composite resin: an in vitro comparison of attachment techniques. Quintessence Int 1989;20(9):629-636. PMID: 2700820

6. Anselm Wiskott HW. Fixed prosthodontics: principles and clinics; 2011. 